\title{
BARRIERS TO IMPLEMENTATION OF LEAN CONSTRUCTION TECHNIQUES IN GUJARAT CONSTRUCTION INDUSTRY
}

\author{
Harshil S. Thakkar ${ }^{*}$ 凶 (D), Vismay A. Shah ${ }^{2}$ \\ ${ }^{* 1,2}$ Department of Civil Engineering, L.J. Institute of Engineering and Technology, Gujarat \\ Technological University, India
}

DOI: https://doi.org/10.29121/ijetmr.v8.i4.2021.905

Article Citation: Harshil S. Thakkar, and Vismay A. Shah. (2021). BARRIERS TO IMPLEMENTATION OF LEAN CONSTRUCTION

TECHNIQUES IN GUJARAT CONSTRUCTION INDUSTRY. International Journal of Engineering Technologies and Management Research, 8(4), 17-24. https://doi.org/10.29121/ijetmr.v8 .i4.2021.905

Published Date: 12 April 2021

Keywords:

Lean Construction Technique Gujarat Construction Industry Barriers to Implement Lean Concept

\begin{abstract}
Lean construction technique has been arisen from endeavouring and applying Japanese lean manufacturing philosophy to the construction industry. Large research is being done recently and an ongoing process to adopt lean principles to the construction industry to enhance the efficacy, amelioration of waste. The success of the lean technique is evident, but some major reports indicated that major challenges are related to the Misconceptualisation of lean thinking, and some case studies have ascertained that the lean technique was either applied partially or erroneously. The purpose of this paper is to elucidate the lean concept, wastes in construction, features of lean project delivery, lean principles and the barriers to implementing the lean technique in the Gujarat construction industry. A compendious review of the literature had been done with the perspective of reaping pertinent data needed for the paper and to make a questionnaire. To check the reliability of data Cronbach's alpha was used. Followed by a statistical analysis of data by Relative Important Index (RII) and ranks were given. Further analysis discovered that only nine of these barriers were determined significant, where dominant factor was Resistance to change and culture with an RII value of 0.63 . The results of this study could be used to help researchers, practitioners and companies in the Gujarat construction industry to fasten their attention on the suggestive issues to the prosperous implementation of the lean concept.
\end{abstract}

\section{INTRODUCTION}

Due to the increase in urbanization, industrialization, growing population base, and infrastructure projects, the Real estate sector and Construction industry has become one of the leading industry in India that also plays a cardinal role in the economy of the country. According to an article in Maier Vidorno, it is the third-largest contributor to economic growth. Furthermore, the construction industry employs more than 40 million people and has a large pool of low-cost workers. Moreover, it has been anticipated that the construction industry in India will be the 3rd largest in the global market by 2025. It has also been speculated by the government that the construction industry in value terms is expected to record a CAGR of $15.7 \%$ to reach $\$ 738.5$ bn by 2022 and the Real Estate sector to reach a market size of US\$ 1 trillion by 2030 from US\$ 120 billion in 2017. Despite this humongous growth and amount to spend, the industry has a lack of management and lack of the effective delivery of a certain project. According to Medows D (2011), Processes in the construction industry are more wasteful than processes in other industries. Moreover, a study discovered that there is $12 \%$ waste in process of manufacturing while $57 \%$ waste in process time for

(c) 2021 The Author(s). This is an open access article distributed under the terms of the Creative Commons Attribution License, which permits unrestricted use, distribution, and reproduction in any medium, provided the original author and source are credited. 
construction of a project (Aziz and Hafez, 2013; Lean Construction Institute, 2004). Similarly, in the Indian construction industry, the lack of skilled labourers and good workmanship sometimes questions the quality of work.

To obviate the issues in management, waste in the process and increase the efficacy Lean technique was introduced in Japan for the manufacturing in the automotive industry to eliminate it. Consequently, Toyota grew to be the world's leading automotive industry by adopting seven principles of reducing waste. Due to those benefits, the Lean technique now can be applied in the construction industry as well. Therefore, efforts to increase the effectiveness of the construction industry or build industry Lean technique has been applied all over the globe to ameliorate the waste and designed to make projects sustainable, achieving sustainability of in building projects delivery is plausible by using technology and making the project leaner.

In recession time, owner expectations were increased in compared to the project delivery that managers were able to provide in less cost as the design of a project was costly due to many issues and errors begot as the project continued. Lean design by Sam spata can be stated as "A creative process that prevents error and invents value." Furthermore, he stated that lean is perhaps the best risk management device we have right now and it is an operational strategy and it delivers increased efficacy by a flow deficiency.

A critical evaluation of the application of lean techniques and principles will help a making place for valueadding, waste reduction, and efficient delivery in time in the Gujarat construction industry for the good and benefit of all manifold. The core objective of this study is to determine barriers to the implementation of lean in construction projects in Gujarat. Given the complex nature of most construction projects and the ensuing difficulty arising therefrom, the Gujarat construction industry must contribute to the economy by deploying value-adding activities and waste reduction strategies, delivery in time to achieve competitive advantage in the industry. The achievements of these objectives in this paper will help stakeholders in the Gujarat construction industry to develop appropriate solutions to overcome these barriers.

\subsection{CONCEPT OF LEAN CONSTRUCTION}

The principal idea is to maximise customer value while abetting waste, furthermore, it can be simplified as a means to create more value. Lean technique understands customer value and focuses its key processes to continuously appreciate it. The principal agenda is to provide perfect value to the patrons through a perfect value creation process that has nominal or zero waste. To achieve this, lean thinking changes the focus of management from optimising individual technology, assets, departments and agencies, to optimising the flow of products and services through entire value streams that flow evenly across technologies, assets, and departments to customers. It also enables the flow of steps by ruling out the non-value added activities which are resources, time or space consuming. It focuses on process improvement through the reduction of duration for each activity. The concept of lean provides the base for the effective management of the project.

\subsection{LEAN PRINCIPLES}

- Identify value:- What customers value the most and what the team that has been organised for work values to discrete the value-adding from waste activities. Because value is everything that customer pays for.

- Map the value stream:- Identify all the steps in the value stream for each product or family, closing out the steps which do not add any value to the project to deliver the project efficiently

- Create flow:- Make the value-creating steps occur in sequence so the product will flow smoothly and with better-integrated disciplines and iterations.

- Use Pull logistics:- All components and information of the work are made and supplied at a predetermined time and to produce what customers want by obviating delays and overproduction.

- Pursue Perfection:- A cardinal part of the lean concept is continuous improvement. Continuous improvement can be achieved with the help of method like Plan-Do-Check-Act, known as PDCA to deplete the waste. 
Harshil S. Thakkar, and Vismay A. Shah

\subsection{WASTE IN CONSTRUCTION}

There are 8 types of waste in the construction of a project

- Over/under production

- Waiting

- Excess inventory

- Defects

- Over-processing

- Unnecessary transportation

- Unused employee creativity

- Unnecessary motion

\subsection{FEATURES OF THE LEAN PROJECT DELIVERY SYSTEM}

Sam spata opined that lean project delivery is "A project management process that strips away unnecessary effort, time and cost in the planning, design and construction of the capital project to deliver what the owner values." Elements essential to Lean project delivery are Target Value Design, Pull Planning, Set-Based Design, and Choosing by Advantages.

He further classified Key features of the Lean Project Delivery system

- The delivery system is the focus, not the parts (lean culture)

- As variation is reduced, reliability increases (Percent Promises Completed)

- Contingencies mutually defined around "sticky" variability (Integrated Project Delivery)

- Necessity self-imposed to force innovation (Target Value Design)

- Flow where you can, Pull where you can't, Push where you must (Last Planner)

- Action taken at last responsible moment (Set-Based Design)

- Product and process are designed together (A3)

- Standards: the starting point for improvement (plus/delta)

- All product life cycle stages are considered in design (Choosing By Advantages)

- Interests aligned (relational contracts)( Integrated Project Delivery)

\subsection{LITERATURE REVIEW OF BARRIERS TO IMPLEMENTATION LEAN TECHNIQUE}

Existing data and literature on lean principles and their application in the construction industry all over the globe were collected. Moreover, barriers to implementing the lean technique were also investigated.

Vinaya D. more et al. (2016) found in the study lack of communication between contractor, and team of owner and designer is one of the barriers to applying the lean technique. Furthermore, they did imply lean technique in the project and found out that technique helped to reduce $25 \%$ of total duration and $13 \%$ of reduction in process activities.

Ogunbiyi (2014) in his study on the implementation of the lean approach in sustainable construction in the U.K., found out the key barriers to lean implementation which was classified as following, resistance to change and culture; employees attitudinal issue; lack of management support; lack of customer-focused and process-based performance measurement systems; lack of adequate lean awareness and understanding; and lack of implementation understanding and concepts are some of the most severe barriers to the implementation of lean.

Amade. B et al. (2019) discovered in their thesis that barriers of applying the lean technique in the Nigerian construction industry were, lack of adequate lean awareness and understanding; resistance to change and culture; lack of technical capabilities; lack of financial resources; government attitude to innovation and lack of top management commitment and support.

Radhika R and S. Sukumar(2017) ascertained that equipment breaks down, work structure, external delays, poor material management were the causes of less application of lean management. Moreover, if these can be eliminated, increased profitability, elimination of hazard, better quality of materials, improved work efficiency can be achieved. 
Sam spata (2018) in his class demonstrated the case study of two similar projects with the same time, city, architect, Bid cost, but with a different contractor, delivery method. One project had delivered with the traditional method and the other was with the lean delivery system. Consequently, a project with traditional delivery exceeded bid cost and had to do major changes and cost after completion was approximately 1.38 million $\$(15 \%)$ more than a project with the lean delivery system.

Devaki M.P. And R. Jayanthi illustrated in their research that Lack of exposure to the need for lean Construction, Uncertainty in the supply chain, the tendency to apply traditional management were the top 3 major barriers to the application of lean system in the Indian construction industry.

\section{METHODOLOGY}

The paramount tool for the retrieval of data to conduct the research and analyse comprises questionnaires. The questionnaire was prepared after sheer study of literature and by understanding the lean construction techniques with their benefits and challenges. The questionnaire survey was created with help of an online Google form and was mailed to major construction firms located in Gujarat.

The questions in the survey were based on the previous literature studies conducted on this topic. The questionnaire was divided into two sections: the first section collected demographic characteristics of the target population i.e. the name, education, firm name, work experience etc. The second section, which was crucial, was based on global factors, which were identified from the literature review. Those Questions were framed in yes/no type format so that they can be easily answered and wouldn't take much time. Some questions listed were asked to scale from 1 to 5 with respect to their probability of occurrence. The targeted population included civil engineering professionals including contractors, site engineers, government employees, project managers, builders, architects etc. And they were requested to answer the same as per their perspective. The 47 questions were asked in the survey which was pertinent to the major barriers to implementing the method. The answers were analysed on the probability of their occurrence and the most probable barriers are listed in the result. The answers to the questionnaire received were compiled so that we could have a lucid view of the most probable barriers.

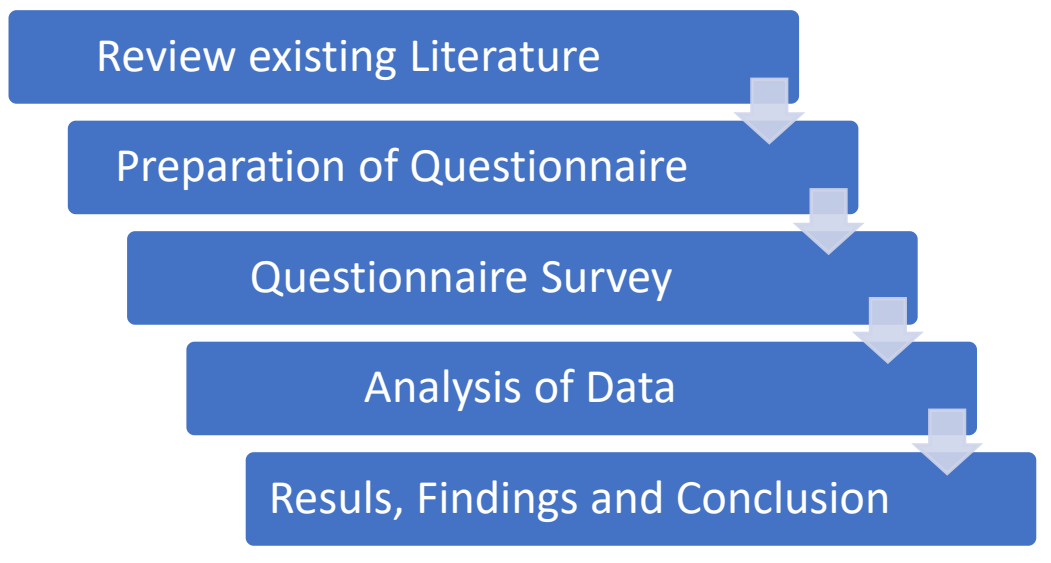

Figure 1: Methodology

The content validity of the questionnaire was established by the researchers by seeking the opinions of experts in the field. Moreover, in terms of reliability, Cronbach's alpha was used to check the reliability of the instrument which is based on the internal consistency of the research instrument. To rank the barriers, the data collected through the survey were analysed by using The Relative Important Index (RII) which was computed by chan and Kumaraswamy (2002) using the formula.

$$
\mathbf{R I I}=\Sigma \mathbf{W} /\left(A^{*} \mathbf{N}\right)
$$

Where $\mathrm{W}$ is the weighting given to each factor by the respondents (ranging from 1 to 5 ), $\mathrm{A}$ is the highest weight (i.e. 5 in this case), and $\mathrm{N}$ is the total number of respondents. Higher the value of RII, more important was the Barrier to implement the method. 


\section{RESULTS AND DISCUSSIONS}

The questionnaire was sent to 139 major construction firms and employees in Gujarat, but due to busy schedules some employees neglected to answer and 94 responses were collected. The initial aspect of the questionnaire captured the respondent's characteristics concerning their vocation, qualifications, years of experience in the industry, the name of the firm.

Table 1 demonstrates the background information of the respondents regarding the organisational characteristics, $19.15 \%$ of the total respondents who were contractor, $36.17 \%$ were working as a site engineer/supervisor in the company, $25.53 \%$ were the project managers/consultants, $10.64 \%$ were an architect, and $8.51 \%$ were Builder. Thus, it could be interpreted that the majority of respondents were working at the construction site and the rest were working outside the site. Table 2 depict information regarding the academic qualifications of the interviewee, the majority had done (57\%) bachelor's degree or diploma in civil engineering/architecture and the rest of them had a master's degree or doctorate in civil engineering/architecture. Table 3. indicate work experience of respondents, $52.13 \%$ of total respondents have had the experience of 1-5 years, $27.66 \%$ had experience of 5-10 years, $8.51 \%$ had been in the industry for $10-15$ years and the rest of $11.71 \%$ had the experience of $15+$ years. To check the reliability of background information some of them were randomly selected and were interviewed.

Table 1: Organizational characteristics

\begin{tabular}{|c|c|c|}
\hline Work Position & Respondents & Percentage $\%$ \\
\hline Contractor & 18 & $19.15 \%$ \\
\hline Site Engineer/Supervisor & 34 & $36.17 \%$ \\
\hline Project manager/consultant & 24 & $25.53 \%$ \\
\hline Architect & 10 & $10.64 \%$ \\
\hline Builder & 8 & $8.51 \%$ \\
\hline Total & 94 & $100.00 \%$ \\
\hline
\end{tabular}

Table 2: Academic Qualification

\begin{tabular}{|c|c|c|}
\hline Academic Qualification & Respondents & Percentage \% \\
\hline Diploma in Civil Engineering & 11 & $11.70 \%$ \\
\hline Bachelors in Civil Engineering & 36 & $38.30 \%$ \\
\hline Masters in civil engineering & 33 & $35.11 \%$ \\
\hline Masters in Architecture & 2 & $2.13 \%$ \\
\hline Bachelors in Architecture & 7 & $7.45 \%$ \\
\hline PhD in civil Engineering/Architecture & 4 & $4.26 \%$ \\
\hline Others & 1 & $1.06 \%$ \\
\hline Total & 94 & $100.00 \%$ \\
\hline
\end{tabular}

Table 3: Work Experience

\begin{tabular}{|c|c|c|}
\hline Years Of Experience & Respondents & Percentage $\%$ \\
\hline 1-5 Years & 49 & $52.13 \%$ \\
\hline 5-10 Years & 26 & $27.66 \%$ \\
\hline 10-15 Years & 8 & $8.51 \%$ \\
\hline 15-25 Years & 7 & $7.45 \%$ \\
\hline 25+ Years & 4 & $4.26 \%$ \\
\hline Total & 94 & $100.00 \%$ \\
\hline
\end{tabular}

To check the reliability of the answers of the latter section, Cronbach's alpha was determined and data were corroborated. The outcome of the internal consistency of the individual categories of constructs through Microsoft Excel spreadsheet. Cronbach's alpha value ranges between $0-1$, where 0 is the weakest and 1 the strongest. Alpha 
values within this range; $\alpha \geq 0.9$ excellent; $0.9>\alpha \geq 0.8$ good; $0.8>\alpha \geq 0.7$ acceptable; $0.7>\alpha \geq 0.6$ questionable; 0.6 $>\alpha \geq 0.5$ poor; $0.5<\alpha$ unacceptable (George $\&$ Mallery, 2003). In the survey, it was discovered that the alpha of this survey was 0.88 which was good and the data found to be trustworthy.

In fig.2 it could have been seen that when it was asked, whether a person has known/heard about the lean construction technique, $48.94 \%$ responded positively and $51.06 \%$ had no idea about the method. It was later found out that the lean technique was included in some of the post-graduation courses so that people may have been familiar with the method. But, to know whether they apply the technique in their respective project or not directly or indirectly was later discovered through the Main section in the questionnaire.

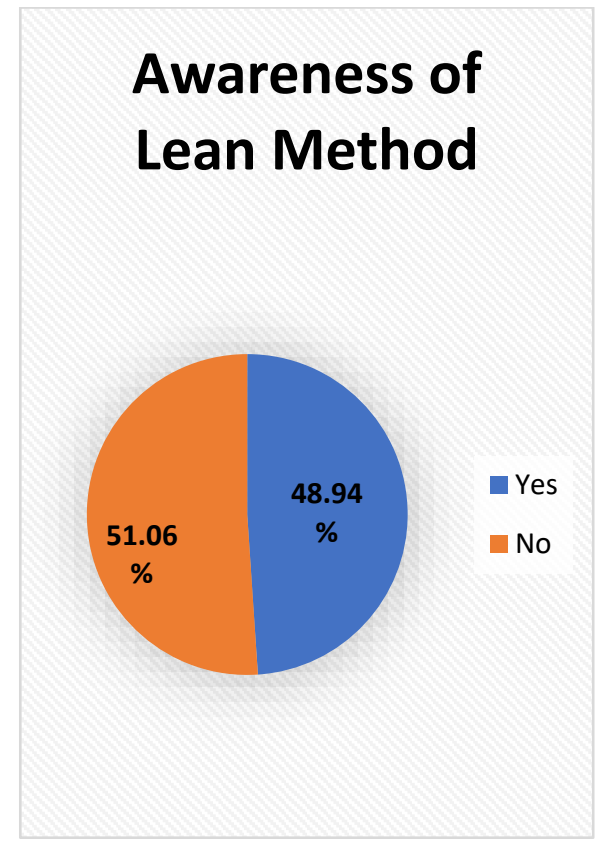

Figure 2: Awareness of Lean Method

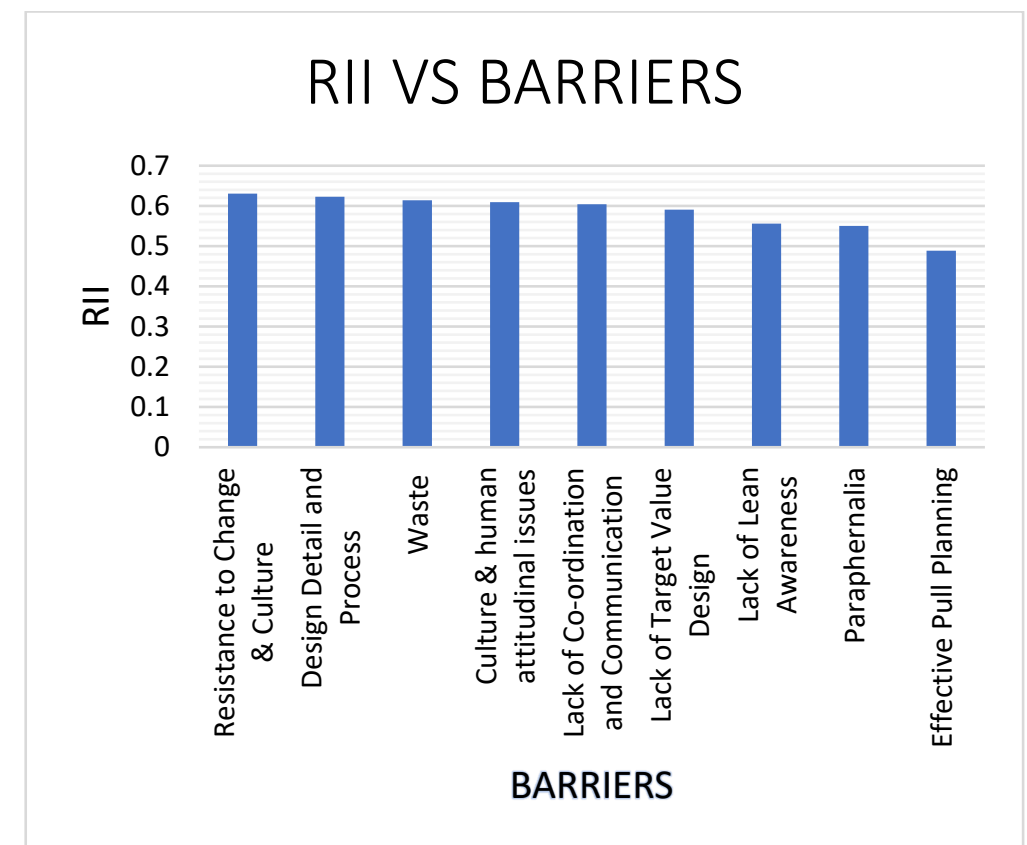

Figure 3: Barrier to Implementation of Lean Principles in Gujarat

The respondents were requested to indicate their answers to the questions on a scale of 1 to 5. Questions were pertinent to the nine barriers to lean implementations that were identified from the literature. Table 5 depicts that the most important barrier to lean implementation as stated by interviewees is "Resistance to change and culture" with an RII of 0.63 and ranked first. It was due to the Gujarat construction industry lacked technology at the project site, like updating data and retrieving the information from different agencies. Some firms still use the traditional method as they don't want to disturb what is working. It was found out in the survey that rather than adopting cloud base software, daily tasks were updating the data manually in a note book. "Design Detailing and Process" was the $2^{\text {nd }}$ major barrier according to respondents with an RII value of 0.62 . On account of, time waste in the processing and designing of a particular part of the project. As the partisans of the Lean principles believe in spending minimum time and money in detailed designing or detailed pre-estimates. "Waste in the project" and "Culture \& Human Attitudinal Issues" both barriers were ranked $3^{\text {rd }}$ as they had the same value of RII of 0.61. Waste in the Gujarat construction sector was in form of defects in material, an activity that adds no value, large inventory, and overproduction. Whereas on the other hand, human attitudinal issues were due to lack of authority/responsibilities, overtime work, low wages. According to interviewees, the industry had Poor communication between different agencies, top management and lower management. So, "Lack of Co-ordination and Communication" had been given the fifth rank with an RII value of 0.60. Although "Lack of Lean Awareness" was found to be a dominant factor in the majority of literature, it had an RII value of 0.56 and was not as significant in Gujarat. Finally, the results ascertained that Effective Pull Planning had the least RII value of 0.48 among all barriers and was ranked ninth. 
Harshil S. Thakkar, and Vismay A. Shah

Table 4: Cronbach's Alpha Value

Reliability Statistics

Cronbach's Alpha $\quad 0.88$

Table 5: Relative Important Index for Barriers to the Implementation of Lean Principles

\begin{tabular}{|c|c|c|c|}
\hline ID & Barriers & RII & Rank \\
\hline 1 & Lack of Lean Awareness & 0.56 & $6^{\text {th }}$ \\
\hline 2 & Effective Pull Planning & 0.49 & $8^{\text {th }}$ \\
\hline 3 & Lack of Co-ordination and Communication & 0.60 & $4^{\text {th }}$ \\
\hline 4 & Resistance to Change \& Culture & 0.63 & $1^{\text {st }}$ \\
\hline 5 & Culture \& human attitudinal issues & 0.61 & $3^{\text {rd }}$ \\
\hline 6 & Design Detail and Process & 0.62 & $2^{\text {nd }}$ \\
\hline 7 & Lack of Target Value Design & 0.59 & $5^{\text {th }}$ \\
\hline 8 & Waste & 0.61 & $3^{\text {rd }}$ \\
\hline 9 & Paraphernalia & 0.55 & $7^{\text {th }}$ \\
\hline
\end{tabular}

\section{CONCLUSION AND RECOMMENDATION}

The construction industry is fragmented and dynamic. Therefore, the construction industry is dealing with several uncertainties and claims as well as safety, quality, productivity, project delivery, and waste problems. To preclude and make improvements in these aspects, the lean technique was introduced in the construction sector. This is the first comprehensive empirical study in the Gujarat construction industry aiming at assessing the implementation of lean construction in Gujarat. Hence, it could be viewed as an initial step towards building a strong understanding of lean technique among the construction project manager in Gujarat. Although, it was discovered that $48.94 \%$ of all respondents were aware of the lean method, but they were not able to imply it successfully had some misconception about the method. The technique is still in infancy in Gujarat and had a few barriers to apply it successfully.

From the outcomes of the result, the study now concludes that the nine barriers were in the Gujarat construction industry, which was identified and evaluated. The dominant barrier in the findings was Resistance to change and culture. To overcome this barrier practitioners could use new technologies like BIM modelling, make preschedules, update daily tasks in an online portal, or train the employees and make them aware of novel methods which are dominant in the market. The second barrier, design detailing and process, can be prevailed by making parametric estimates rather than detailed estimate or by curtailing time in the designing process. Furthermore, other major obstacles were pertinent to waste, culture and human attitudinal issues, and lack of coordination and communication. These can be subdued by proper material management, motivating the employees/workers, and improving communication technique between different agencies. The findings of this study could prove valuable to other states in India as well as in other countries, especially those sharing similarities to the Gujarat, India context. Finally, more research and primordial need to carry out case studies in different construction companies to conceive a roadmap for lean construction implementation in the Gujarat construction industry.

\section{SOURCES OF FUNDING}

This research received no specific grant from any funding agency in the public, commercial, or not-for-profit sectors.

\section{CONFLICT OF INTEREST}

The author have declared that no competing interests exist. 


\section{ACKNOWLEDGMENT}

The authors record their appreciation for the time and effort taken by the respondents to complete the questionnaire survey, despite their hectic schedule.

\section{REFERENCES}

[1] Amade, B., Ononuju, C., Obodoh, D. A., And, \& Okorie, C. (2019). Barriers to Lean Adoption for Construction Projects.

[2] Aziz, R. F., \& Hafez, S. M. (2013). Applying lean thinking in construction and performance improvement. Alexandria Engineering Journal, 52(4), 679-695. https://doi.org/10.1016/j.aej.2013.04.008

[3] Bajjou, M. S., \& Chafi, A. (2018). Lean construction implementation in the Moroccan construction industry: Awareness, benefits and barriers. Journal of Engineering Design and Technology, Volume 16, 533-556. https://doi.org/10.1108/JEDT-02-2018-0031

[4] Barriers to Implementation of Lean Principles in the Indian Construction Industry. (2014). International Journal of Engineering Research, 3(5), 4.

[5] Bhatnagar, R., Kim, J., \& E. Many, J. (2014). Candidate Surveys on Program Evaluation: Examining Instrument Reliability, Validity and Program Effectiveness. American Journal of Educational Research, 2(8), 683-690. https://doi.org/10.12691/education-2-8-18

[6] Chan, D. W., \& Kumaraswamy, M. M. (n.d.). A comparative study of causes of time overruns in Hong Kong construction projects. International Journal of Project Management, 15(1), 55-63.

[7] Corbett, V. (n.d.). Construction Industry in India | Overview \& Statistics | Maier+Vidorno. Maier and Vidorno. Retrieved March 26, 2021, from https://www.maiervidorno.com/industry-expertise/construction/

[8] George, D. and P. Mallery. 2003. SPSS for Windows Step by Step: A Simple Guide and Reference. 11.0 update (4th ed.). Allyn \& Bacon: Boston, MA.

[9] Indian Real Estate Industry: Overview, Market Size, Growth, Investments...IBEF. (n.d.). Retrieved March 26, 2021, from https://www.ibef.org/industry/real-estate-india.aspx

[10] Lean Design and Delivery. (n.d.). Coursera. Retrieved March 26, 2021, from https://www.coursera.org/learn/construction-project-management/home/week/2

[11] Meadows, Dru. Designing out waste. Environmental Design \& Construction. http://www.edcmag.com/articles/87434-designing-out-waste\#comments (accessed July 29, 2011).

[12] More, V. D., Charhate, D. S., \& Sinha, M. (n.d.). Lean Construction Techniques in Indian Construction Industry: Some Analysis. 8.

[13] Ogunbiyi, O. (n.d.). Implementation of the Lean Approach in Sustainable Construction: A Conceptual Framework. 412.

[14] R, R., \& Sukumar, S. (2017). AN OVERVIEW OF THE CONCEPT OF LEAN CONSTRUCTION AND THE BARRIERS IN ITS IMPLEMENTATION. International Journal of Engineering Technologies and Management Research, 4(3), 13-26. https://doi.org/10.29121/ijetmr.v4.i3.2017.78

[15] Spata, S. (n.d.). Introduction to Lean in Design. 97. 